\title{
Social Work Role in Pain Management with Hospice Caregivers: A National Survey
}

Debra Parker Oliver, MSW, PhD [Associate Professor], Family and Community Medicine, University of Missouri, Columbia

Elaine Wittenberg-Lyles, PhD [Assistant Professor], Department of Communication Studies, University of North Texas, P. O. Box 305189, Denton TX 76203-5189

Karla Washington, $\mathrm{PhD}$, and

University of Louisville, School of Social Work

Seema Sehrawat, PhD

University of California-Chico, School of Social Work

\begin{abstract}
This article reports on an exploratory study of hospice social workers' assessment and collaborative practices related to pain management; especially caregiver concerns about patient pain. A nonrandomized national survey indicated that social workers assess the components of pain but are not able to devote as much attention to it as they feel is needed. While most reported assessing patient and family needs, many do not use standardized assessment instruments. These data suggested that while social workers may understand their role in pain management they struggled for the time and tools needed to help address caregiver concerns related to pain management. This study suggests that the development of standardized assessment instruments for hospice social workers would be helpful and points to the value of team training and discussion about ways the social worker can best assist caregivers with pain management issues. Research is needed on social work interventions with caregivers related to pain to establish an evidence base for hospice social work, cement a role identity for social work in pain management, and facilitate increased interdisciplinary collaboration to improve the team response to all aspects of pain.
\end{abstract}

\section{Keywords}

Social Work; hospice; interdisciplinary team; pain management; assessment

\section{Introduction}

Recent research has reported that informal caregivers of hospice patients are not routinely assessed by social workers or any member of the hospice team, including their perceptions of pain medicines (Parker Oliver et al., 2008). The purpose of this study was to follow-up on those findings and assess if the issue was isolated to the hospices participating in the earlier study or if the lack of formal caregiver assessment by social workers is more widespread.

While social workers can play an essential role in supporting caregivers involved in pain management, many barriers to the effective implementation to this role exist. Specifically, 
studies conducted in Australia, United Kingdom, and the United States all noted that hospice social workers have struggled with role definition, status, and identity issues (Lloyd-Williams, Friedman, \& Rudd, 1999; MacDonald, 1991; Reese \& Raymer, 2004; Ryan, 1996). Other barriers for social workers that have been identified include a lack of knowledge of other professions, role blurring, conflicts in values and theoretical approaches with other team members, negative team norms, client stereotyping, and various administrative issues (Reese \& Sontag, 2001).

Despite these challenges, social workers must respond to both ethical and practical mandates to become full partners with the team in addressing pain management. Social workers need only examine their Code of Ethics to see that social work values are consistent with the principles guiding pain management, including the alleviation of suffering. (Altilio, OtisGreen, Hedlund, \& Fineberg, 2006). Research has also demonstrated the tremendous value in the social work role. Increased social work involvement has been found to lower hospice costs and facilitate team functioning, reduce the need for additional medical services, and decrease the number of non-scheduled visits by other team members. Finally, social work involvement has been shown to be associated with increased client satisfaction (Reese \& Raymer, 2004).

Social workers achieve these impressive results in a variety of ways. For example, social workers use communication skills to facilitate assessment of the family's needs and enable the healthcare team along with the family to mobilize necessary resources (Monroe, 1993). The information gained through assessment and regular monitoring of informal caregiver needs helps the team to develop intervention strategies that target the identified issues (Barnes \& Given, 1992). Terry Altilio, Social Work Coordinator in the Department of Pain Medicine and Palliative Care at Beth Israel Medical Center, has suggested specific ways social workers can assist with pain management including mediation of the impact of pain, exploring the relationship between the physical, psychological, emotional, and spiritual aspects of pain, and understanding how history, values and beliefs impact the experience of pain (Altilio, 2009).

While the literature related to the role of social workers in hospice has grown in recent years, a dearth of research related to the social work role in pain management still exists. Some authors have called attention to the need for education of social worker regarding pain management (Parker Oliver, Porock, Demiris, \& Courtney, 2005). Research that specifically explores the knowledge of social workers and the role of social work in pain management, especially with caregivers, is absent from the peer-reviewed literature. MacDonald (1991) observed in the early 1990's that social workers were searching for an identity on hospice teams. This observation seems particularly relevant today in terms of the efforts social workers are making to establish a credible role in pain management.

Family caregivers of hospice patients are often responsible for administering pain medication. Further, many report a high degree of uncertainty as it relates to the responsibilities of managing pain at home (Keefe et al., 2003; Parker Oliver et al., 2008). Caregivers' responsibilities for managing patients' pain include assessing of patient pain, preparing and administering medications, monitoring symptoms, trouble-shooting medication side effects, and communicating with medical staff (Keefe et al., 2003). Much of the uncertainty around these activities stems from the fear of making a mistake, giving too much medication and/or giving medication at the wrong time, and misperceptions about the risk of addiction and drug tolerance (Arrand et al., 2004; Kazanowski, 2005). Attitudes, beliefs, and fears associated with pain and symptom management impact the caregiver's decision to give scheduled medications and thus may create barriers to effective pain management. 


\section{Conceptual Model}

Although grounded in oncology, the hospice philosophy as developed by Cicely Saunders (Saunders, 1986) uses the term "total pain" to refer to all aspects of the pain experience. The current study relied on an integrated psychosocial-spiritual model of cancer pain management (Otis-Green, Sherman, Perez, \& Baird, 2002). This model posits that pain is multifaceted and consists of physical, emotional, cognitive, social, behavioral and spiritual components. The various components are interrelated and reciprocal in their effects, with each aspect playing a role in the total experience of pain. Advocates of this approach assume that treatment of pain requires the skills of an interdisciplinary team collaborating closely together with mutual respect and open communication and with the shared goal of managing the patient's total pain. Additionally, the model advocates the involvement of a licensed clinical social worker whose role includes the assessment of the patient and the family, specifically assessing information related to the psychosocial components of pain. It is implied that the social worker's assessment will be communicated to other team members and psychosocial interventions will be designed to assist the patient and family in the management of pain.

\section{Purpose of Study}

The goal of this project was to explore the assessment and collaboration practices of hospice social workers related to the psychosocial components of pain, especially caregiver concerns of pain management. A survey was developed to identify the answers to three research questions among a convenience sample of social workers. The questions underlying this study included: 1) How do hospice social workers assess pain; 2) How do hospice social workers include caregivers in pain assessments; and 3) How do hospice social workers collaborate with their teams to address psychosocial components of pain, especially as they relate to caregivers?

\section{Methods and Procedures}

A national survey was used to answer the research questions listed above. The Institutional Review Board of the sponsoring university approved this study. The survey was created based upon the findings of an earlier pilot study that explored the assessment of caregivers perceptions of managing their patient's pain (Parker Oliver et al., 2008). The survey asked questions related to the delivery of social work services in their hospice, the social workers' role within the team, their assessment and experience with caregivers related to pain management and their team meeting structure. The instrument was presented to the Advisory Board of the Population Based Palliative Care Research Network (PoPCRN) for review and approval for use with the research network. While no data are available to determine the representativeness of the PopCRN network to all hospice programs, it does allow for access to programs willing and interested in participating in research. The PoPCRN network, established in 1998, has the mission to facilitate research in palliative care and connect researchers with hospice practitioners. The research network consists of 101 hospices from across the US interested in participating in research studies. Previous survey research by this team and others with the PoPCRN hospices have been successful (Fischer, Egan, Kassner, \& Kutner, 2005; Johnson, Kassner, \& Kutner, 2004; Washington, Demiris, Parker Oliver, \& Day, 2009).

Participants were recruited for the survey in two ways. First, the PoPCRN newsletter published two recruitment notices directing interested participants to the survey website. Second, the listed network contact for each PoPCRN hospice was called and asked to forward the information to their social work staff. Staff were then able to go directly to the website or request a mailed paper survey form.

Responses were downloaded from the website and returned mail surveys were entered into an SPSS database for analysis. Data were screened to ensure they satisfied the assumptions 
required to proceed with statistical analysis. All variables in the analysis were screened for missing data and normality. A small number of randomly scattered missing values were identified. Group means were calculated based on the available data and used to replace the missing values as recommended by Chatterjee (Chatterjee, Bailey, \& Aronoff, 2001).

\section{Results}

\section{Participants}

The listed PoPCRN contacts (usually administrators), were asked to distribute the survey to social workers in their agencies. It is unknown how many were actually received by individual social workers; therefore, a response rate cannot be calculated. Of the total 90 total respondents, $74(83 \%)$ completed the web-based questionnaire. The remaining $16(17 \%)$ completed hard copies that were returned by mail. Responses were received from social workers employed by hospices in 19 states across the country. The majority of social workers held a Masters degree (74\%). Survey questions and their responses are detailed in Table 1.

The average daily census of the hospice programs represented in the survey data ranged from 13 to 1000 patients per day, with a mean of 234.5 patients. This is higher than expected, as the mean average daily census of all US hospices, as reported by the National Hospice and Palliative Care Organization, was 90.2 patients in 2007 ; only $18.5 \%$ hospices served more than 100 patients per day (National Hospice and Palliative Care Organization, 2008). Finally, social workers responding to the survey had significant hospice experience ranging from three months to 20 years with the mean number of six years. Responding social workers reported a range of one to 80 social workers in the agency with a mean number of 13 social work colleagues.

\section{Social Work Practices}

On average, social workers reported devoting approximately $21 \%$ of their time to pain management issues (table 1 survey item 6). In contrast, they reported wishing they could spend $28 \%$ of time handling pain management concerns (table 1 survey item 7 ). Although the majority of social workers $(68.9 \%)$ reported that they assess caregiver attitudes toward pain medicine, a significant number (13.3\%) do not routinely make this assessment. A majority (55.6\%) of respondents reported they use a standard form to assess family and caregiver needs. On a scale of 1 (never discuss) to 10 (always discuss), social workers reported a mean of 7.58 relative to the frequency of discussion with the caregiver about physical pain (range of 3-10). Similarly, they reported 8.2 for discussions of psychological pain (range of 1-10), 7.5 for social pain (1-10 range) and 6.2 for spiritual pain (1-10 range).

Over one-fourth $(25.5 \%)$ of the survey respondents reported they were approached by their non-social work colleagues at least once every day or every other day to assist with caregiver concerns related to pain management. Slightly less than one fourth (23.3\%) reported they were approached to assist with caregiver concerns at least once a week, and $11.1 \%$ reported being asked once a month. Likewise, other team members ask social workers for one-on-one assistance with concerns related to caregiver pain management. Among survey respondents, $14.5 \%$ reported being approached by other team members to provide one-on-one assistance with pain management every day or every other day, $16.7 \%$ reported at least once a week, and $23.3 \%$ once a month.

The length of interdisciplinary team (IDT) meetings, held to facilitate collaboration among the various disciplines, ranged greatly among survey respondents (one hour to four hours). The mean reported time of a team meeting was approximately 2 hours. Most social workers (77.8\%) reported feeling like active participants in the team meetings. About one-half $(51.5 \%)$ of those surveyed stated they had provided leadership for the team meetings. Almost one-half $(n=37)$ 
of those responding to the question (table 1 survey item 19) felt that equal time/significance was given to each discipline during the team meetings while the remaining respondents $(n=38)$ felt they were not. Nearly $16.7 \%$ did not respond to this question.

The final portion of the survey included the opportunity for respondents to provide responses to open-ended questions. Narrative was provided by $69(77 \%)$ respondents related to the types of problems caregivers encountered related to pain management. Respondents noted several concerns within the physical domain of pain management. These included caregivers worrying about side effects, being unable to determine the level of the patient's pain resulting in overmedication, and caregivers being unable to understand underlying causes of pain. Respondents stressed that many caregivers lack knowledge about administering pain medication and may hold inaccurate beliefs about pain management. Respondents listed specific barriers to effective pain management including many caregivers' beliefs that pain cannot be controlled, their desire to keep the patient alert and awake, and their belief that the patient will decline faster due to pain medication. Finally, surveyed social workers reported that caregivers tend to wait a long time before calling hospice if pain medication is not working.

Likewise, survey respondents shared narratives that detailed caregiver concerns that were psychological and social in nature. These concerns included hesitancy to give pain medication, concerns about addiction, difficulty administering pain medication, feeling of powerlessness, anxiety and sadness, disagreement between family members, lack of a consistent caregiver to administer pain medications in timely manner, and the perception of not being listened to by the physician. One social worker wrote:

In the majority of our caregivers....we have caregivers from time to time who will withhold pain meds, because (a) they think it is hastening the patient's death or (b) it takes away [the patient's] alertness and they would rather be awake and communicating than out of pain.

Similarly, another social work respondent noted:

A lot of times people feel like their loved ones are being overmedicated .... they don't understand that it's not necessarily the medication but it's also the disease process. There tends to be some denial that it's the disease and not necessarily the medications.

\section{Limitations and Strengths of the Study}

The exploratory nature of the study has several limitations as well as strengths. A limitation is that the PoPCRN database was used as part of a convenience sampling strategy and may not be representative of all hospices, but rather represents hospices which are supportive of research. Additionally, the average daily census for hospice providers who participated in the study is considerably larger than the national average (NHPCO, 2008). It is not known if social workers perhaps were reporting their numbers inclusive of more than one office or if they were a part of a single larger office. In order to serve large numbers of patients and families, hospice agencies participating in this study were likely to have employed more social workers than smaller agencies with fewer resources. The extent to which the issues identified in this study affect smaller agencies is unknown.

This study also has a number of strengths that merit attention. Participating social workers provided important data lending valuable insight for future research and the development of social work intervention strategies. The response shows an interest in the topic. The respondents were educated (74.4\% MSW) and experienced in hospice for a mean of six years. Additionally, the sample represents a wide variety of hospice types and numerous states from different geographic regions of the US. Social workers responding to the survey are likely to 
be those most interested in the subject of pain and thus results may actually be more positive than for those not involved in the survey.

\section{Discussion}

Social workers reported spending a considerable amount of their time addressing pain related issues; yet, they also reported feeling they should spend more time handling pain management concerns. This difference would indicate that they perceived that all the psychosocial painrelated needs are not being adequately met. The narrative results indicated that social workers were aware of psychological and social concerns with pain management as they mentioned that these were daily issues in their role as a hospice social worker. Social workers understand their role in pain management and struggle to find the time and tools needed to help them address caregiver concerns related to pain management. This study suggests that the development of standardized assessment instruments for hospice social workers would be helpful.

\section{Social workers inclusion of caregivers in pain assessments}

The majority of social workers reported assessing caregivers' attitudes toward pain medicine, however, indicated that they do not routinely make this assessment. While a majority stated they use a standardized form for this assessment, about one-third of the respondents did not have a standardized assessment to guide them. Finally, social workers in this study confirmed previous findings that caregivers do not routinely attend hospice interdisciplinary team meetings as a way to express their concerns related to pain management or participate in decision making about pain management (Parker Oliver, Porock, Demiris, \& Courtney, 2005; Wittenberg-Lyles \& Parker Oliver, 2007). Given the barriers to participation, including the burdens of caregiving and issues involving transportation, the lack of direct participation by caregivers in IDT meetings is not surprising. The lack of direct caregiver participation points to an opportunity and responsibility for social workers to represent caregivers and serve as their advocates by sharing their concerns. This of course is only possible if the social worker has identified issues with a complete assessment of the caregiver issues related to pain medication and management.

\section{Hospice social workers' collaboration with their teams}

Collaboration is an intensive and time-consuming process. The average amount of time hospice staff formally meet is two hours per week (Wittenberg-Lyles \& Parker Oliver, 2007). The overwhelming majority of social workers feel they are active participants in their agencies IDT meetings, although one-half felt that equal time is not given to all disciplines. Nursing was reported to dominate team discussions. Respondents reported frequently interacting with staff regarding pain management issues and that they were often approached for one-on-one assistance in handling caregiver management of pain concerns. While the majority felt that they do contribute to team collaboration, social workers described their participation in the collaborative process as a supportive role to other team members, rather than an equally pivotal role that would include initiating a discussion about caregiver concerns. Survey data revealed that social workers' information sharing in team meetings primarily centers around patient information and facilitating requests by other team members to educate caregivers when concerns arise. In contrast, social workers should be proactively sharing caregiver information and advocating caregiver education based upon a comprehensive caregiver assessment related to perceptions and experiences of the caregivers management of patient pain issues. 


\section{Implications and Conclusion}

These data demonstrate that social workers appreciate the importance of their assessment of the multiple components of pain and perceive that they are not able to devote as much attention to it as is needed. The National Hospice and Palliative Care Organization reported that in 2007 social workers made up $8.2 \%$ of the clinical full-time equivalent staff. While constitutes the third largest clinical component, it is significantly lower than nursing staff which comprises $33.8 \%$ and home health aides who comprise $19.8 \%$ of the hospice clinical staff. Finally, it is noteworthy that the average caseload for a hospice nurse is 11.2 patients while the average caseload for a social worker is more than twice as high at 23.4 patients (National Hospice and Palliative Care Organization, 2008). For social workers to be equal members of the hospice team it is important that they have adequate staffing which allows them to time to focus on identified patient and caregiver concerns.

Education of social workers on pain management is essential. They are in a position to focus on caregivers and specifically assess and address the perceptions of caregivers toward pain medication. As our conceptual model suggests, pain management is an interdisciplinary task that calls for more than just a focus on the physical pain. If caregiver assessment was standardized and interventions specifically targeted and communicated to the interdisciplinary team, the social worker's role related to pain management could be clarified. Moreover, their status would likewise be clarified if the effects of caregiver interventions were found to result in improved pain management for patients.

Hospice administrators may want to consider an investment in social work and an expansion of the role of social workers in pain management, especially related to caregiver concerns. This investment has the potential to reduce the more expensive nursing costs, and potentially reduce the prevalence of "after hours" calls as caregiver knowledge and confidence are strengthened and anxiety is lowered with targeted social work interventions. Investments in social work assessment and interventions that can lessen caregiver fears and increase education and support for caregivers on pain medicine administration are research issues that should be further explored.

Finally, the standardization of social work assessment presents an opportunity for researchers to evaluate current practices and build an evidence base for hospice caregiver interventions related to the management of patient pain. This evidence base has the power to resolve the ongoing identity crisis articulated in the literature by so many hospice social workers (MacDonald, 1991; Parker Oliver \& Peck, 2006; Reese \& Raymer, 2004). After an evidence base is established, the National Association of Social Workers and the Association of Oncology Social Work will have an opportunity to develop precise and evidence-informed assessment and intervention standards for hospice social workers. Hospice orientation and training for social workers could include various aspects of pain management alongside the nursing orientation. The coordinated training and orientation of social workers and nurses in pain management can potentially encourage collaborative practice with an interdisciplinary perspective and interdisciplinary process on this key issue. Orientation for all hospice team members could include case studies demonstrating the value of interdisciplinary collaboration and communication to the management of patient pain.

These data point to a tremendous opportunity for social work researchers and practitioners to build an evidence base for social work pain management practice which includes standardized comprehensive assessment of the caregiver and their fears of pain management. This is not to say social work roles are exclusive of other team members. A strong evidence base for the management of psychosocial aspects of pain would enrich interdisciplinary collaboration and improve the management of total patient pain. After an evidence base for practice is established, 
the profession will be challenged to disseminate the results and provide educate and support social workers and other team members accordingly.

\section{Acknowledgments}

This project was funded by the National Cancer Institute R21 CA120179: Patient and Family Participation in Hospice Interdisciplinary Teams, Debra Parker Oliver, PI.The authors wish to acknowledge the valuable contributions of the Population Based Palliative Care Research Network (PoPCRN) in reviewing of the initial research design and assisting with sampling.

\section{References}

Altilio, T. Improve end-of-life care training for social workers. Topics include pain, spiritual, cultural issues; Hospital Home Health. 2005. p. 102-105.

Altilio T. Pain- How social workers help with pain management. Social Workers help starts here. 2009 Retrieved April 6, 2009. from http://www.helpstartshere.org/health_and_wellness/pain/ how_social_workers_help/pain_-_how_social_workers_help.html\#social_workers.

Altilio, T.; Otis-Green, S.; Hedlund, S.; Fineberg, IC. Pain Management and Palliative Care. John Wiley \& Sons Ltd.; New York, NY: 2006.

Arrand S, Yates P, Edward H, Nash R, Skerman H, McCarthy A. Barriers to effective cancer pain management: A survey of Austrian family caregivers. Eur J Cancer Care 2004;13(4):336-343.

Barnes CL, Given B. Caregivers of Elderly Relatives: Spouses and Adult Children. Health and Social Work 1992;17(4):282-290. [PubMed: 1478554]

Chatterjee P, Bailey D, Aronoff N. Adolecence and old age in twelve communities. J of Sociology and Social Welfare 2001;28(4):121-159.

Fischer SM, Egan K, Kassner C, Kutner JS. Healthcare professional education: a unique role for hospices. American Journal of Hospice \& Palliative Medicine 2005;22(1):32-40. [PubMed: 15736605]

Johnson DC, Kassner CT, Kutner JS. Pain and symptom management. Current use of guidelines, protocols, and care pathways for symptom management in hospice. American Journal of Hospice and Palliative Care 2004;21(1):51-57. 80, 51p. [PubMed: 14748524]

Kazanowski M. Family caregivers' medication management of symptoms in patients with cancer near death. Journal of Hospice and Palliative Nursing 2005;7(3):174-181.

Keefe FJ, Ahles TA, Porter LS, Sutton LM, McBride CM, Pope MS, et al. The self-efficacy of family caregivers for helping cancer patients manage pain at end-of-life. Pain 2003;103(12):157-162. [PubMed: 12749970]

Lloyd-Williams M, Friedman T, Rudd N. A survey of psychosocial service provision within hospices. Palliative Medicine 1999;13(5):431-432. [PubMed: 10659117]

MacDonald D. Hospice social work: a search for identity. Health \& Social Work 1991;16(4):274-280. [PubMed: 1769621]

Monroe, B. Social Work in Palliative Care. In: Doyle, D.; Hanks, G.; MacDonald, B., editors. Oxford textbook of palliative medicine. Oxford University Press; Oxford: 1993. p. 565-573.

National Hospice and Palliative Care Organization. NHPCO Facts and Figures: Hospice Care in America. Journal. 2008. Retrieved from www.nhpco.org

Otis-Green S, Sherman R, Perez M, Baird P. An integrated psychosocial-spiritual model for cancer pain management. Cancer Practice: A Multidisciplinary Journal of Cancer Care 2002;10(Suppl 1):S5865 .

Oliver, D. Parker; Peck, M. Inside the Interdisciplinary Team Experiences of Hospice Social Workers. Journal of Social Work in End of Life and Palliative Care 2006;2(3):7-21. [PubMed: 17387087]

Oliver, D. Parker; Porock, D.; Demiris, G.; Courtney, KL. Patient and family involvement in hospice interdisciplinary teams: A brief study. The Journal of Palliative Care 2005;21(4):270-276.

Oliver, D. Parker; Wittenberg-Lyles, EM.; Demiris, G.; Washington, K.; Day, M.; Porock, D. Barriers to pain management: Caregivers perception and pain talk by hospice interdisciplinary teams. $\mathrm{J}$ of Pain Symptom Management 2008;36(4):374-382. 
Reese DJ, Raymer M. Relationships between social work involvement and hospice outcomes: results of the National Hospice Social Work Survey. Social Work 2004;49(3):415-422. [PubMed: 15281696]

Reese DJ, Sontag MA. Successful interprofessional collaboration on the hospice team. Health \& Social Work 2001;26(3):167-175. [PubMed: 11531192]

Ryan M. 'Walking in a minefield': findings from a survey of social workers in Australian hospice and palliative care programs. Australian Social Work 1996;49(3):47-54.

Saunders C. The nature and nurture of pain control. Journal of Pain \& Symptom Management 1986;1(4): 199-201. [PubMed: 3640793]

Washington K, Demiris G, Oliver D. Parker, Day M. Telehospice acceptance among providers: A multidisciplinary comparison. American Journal of Hospice and Palliative Medicine 2009;25(6): 452-457. [PubMed: 18812614]

Wittenberg-Lyles E, Oliver D. Parker. The power of interdisciplinary collaboration in Hospice. Progress in Palliative Medicine 2007;15(1):6-12. 
Table 1

\section{Summary of survey items}

\begin{tabular}{|c|c|c|c|}
\hline Survey items & $\mathbf{N}$ & & Range \\
\hline $\begin{array}{l}\text { What is the average daily census of your } \\
\text { hospice agency? }\end{array}$ & 90 & 234.5 patients & $(13-1100)$ \\
\hline \multicolumn{4}{|l|}{$\begin{array}{l}\text { What is the highest educational level you } \\
\text { have attained? }\end{array}$} \\
\hline Less than Bachelors degree & 1 & $1.1 \%$ & \\
\hline Bachelors Degree & 19 & $21.1 \%$ & \\
\hline Masters Degree & 67 & $74.4 \%$ & \\
\hline Doctoral Degree & 2 & $2.2 \%$ & \\
\hline $\begin{array}{l}\text { How long have you worked in a hospice } \\
\text { setting (months)? }\end{array}$ & 85 & 71.7 months & $(3-240)$ \\
\hline $\begin{array}{l}\text { How many social workers are employed } \\
\text { by your hospice agency? }\end{array}$ & 84 & 13.3 social workers & $(1-80)$ \\
\hline $\begin{array}{l}\text { How long do your interdisciplinary team } \\
\text { meetings last (minutes)? }\end{array}$ & 84 & 115.6 minutes & $(45-240)$ \\
\hline $\begin{array}{l}\text { What percentage of your work time IS } \\
\text { devoted to handling pain management } \\
\text { issues? }\end{array}$ & 50 & $21 \%$ & $(0-75)$ \\
\hline $\begin{array}{l}\text { What percentage of your work time do } \\
\text { you think SHOULD BE devoted to } \\
\text { handling pain management issues? }\end{array}$ & 50 & $28 \%$ & $(0-90)$ \\
\hline \multicolumn{4}{|l|}{$\begin{array}{l}\text { How often are you approached by } \\
\text { caregivers to address issues related to } \\
\text { pain management? }\end{array}$} \\
\hline Every day & 11 & $12.2 \%$ & \\
\hline Every other day & 12 & $13.3 \%$ & \\
\hline Once a week & 21 & $23.3 \%$ & \\
\hline Twice a week & 6 & $6.7 \%$ & \\
\hline Every other week & 11 & $11.1 \%$ & \\
\hline Once a month & 10 & $11.1 \%$ & \\
\hline Missing & 12 & $13.3 \%$ & \\
\hline \multicolumn{4}{|l|}{$\begin{array}{l}\text { Do you routinely assess caregiver } \\
\text { attitudes toward pain medicine? }\end{array}$} \\
\hline Yes & 62 & $68.9 \%$ & \\
\hline No & 12 & $13.3 \%$ & \\
\hline Missing & 16 & $17.8 \%$ & \\
\hline \multicolumn{4}{|l|}{$\begin{array}{l}\text { Do you use a standard form to assess } \\
\text { family/caregiver information? }\end{array}$} \\
\hline Yes & 50 & $55.6 \%$ & \\
\hline No & 26 & $28.9 \%$ & \\
\hline Missing & 14 & $15.6 \%$ & \\
\hline $\begin{array}{l}\text { Using a scale of } 1-10 \text {, where } 1 \text { is never } \\
\text { discuss and } 10 \text { is always discuss, please } \\
\text { tell us how often you discuss PHYSICAL } \\
\text { PAIN with caregivers. }\end{array}$ & 74 & 7.58 & $3-10$ \\
\hline $\begin{array}{l}\text { Using a scale of } 1-10 \text {, where } 1 \text { is never } \\
\text { discuss and } 10 \text { is always discuss, please } \\
\text { tell us how often you discuss } \\
\text { PSYCHOLOGICAL PAIN with }\end{array}$ & 74 & 8.2 & $1-10$ \\
\hline
\end{tabular}




\begin{tabular}{|c|c|c|c|}
\hline $\begin{array}{l}\text { Survey items } \\
\text { caregivers. }\end{array}$ & $\mathbf{N}$ & & Range \\
\hline $\begin{array}{l}\text { Using a scale of } 1-10 \text {, where } 1 \text { is never } \\
\text { discuss and } 10 \text { is always discuss, please } \\
\text { tell us how often you discuss SOCIAL } \\
\text { PAIN with caregivers. }\end{array}$ & 74 & 7.5 & $1-10$ \\
\hline $\begin{array}{l}\text { Using a scale of } 1-10 \text {, where } 1 \text { is never } \\
\text { discuss and } 10 \text { is always discuss, please } \\
\text { tell us how often you discuss } \\
\text { SPIRITUAL PAIN with caregivers. }\end{array}$ & 73 & 6.2 & $1-10$ \\
\hline \multicolumn{4}{|l|}{$\begin{array}{l}\text { How often do you share information } \\
\text { about caregivers in team meetings? }\end{array}$} \\
\hline Never & 56 & $62.2 \%$ & \\
\hline Seldom & 17 & $18.9 \%$ & \\
\hline Often & 2 & $2.2 \%$ & \\
\hline All the time & 0 & 0 & \\
\hline Missing & 15 & $16.7 \%$ & \\
\hline \multicolumn{4}{|l|}{$\begin{array}{l}\text { How often are you approached by other } \\
\text { team members to assist with caregiver } \\
\text { concerns about pain management? }\end{array}$} \\
\hline Never & 2 & $2.2 \%$ & \\
\hline Seldom & 4 & $4.4 \%$ & \\
\hline Often & 27 & $39 \%$ & \\
\hline All the time & 42 & $46.7 \%$ & \\
\hline Missing & 15 & $16.7 \%$ & \\
\hline \multicolumn{4}{|l|}{$\begin{array}{l}\text { Outside of team meetings, how often do } \\
\text { you provide other team members with } \\
\text { one-on-one assistance related to caregiver } \\
\text { pain management issues? }\end{array}$} \\
\hline Every Day & 5 & $5.6 \%$ & \\
\hline Every Other Day & 8 & $8.9 \%$ & \\
\hline Once a week & 15 & $16.7 \%$ & \\
\hline Twice a week & 5 & $5.6 \%$ & \\
\hline Every other week & 8 & $8.9 \%$ & \\
\hline Once a month & 21 & $23.3 \%$ & \\
\hline Other & 13 & $14.4 \%$ & \\
\hline Missing & 15 & $16.7 \%$ & \\
\hline \multicolumn{4}{|l|}{$\begin{array}{l}\text { Would you define your role as an active } \\
\text { participant in hospice interdisciplinary } \\
\text { team meetings? }\end{array}$} \\
\hline Yes & 70 & $77.8 \%$ & \\
\hline No & 5 & $5.6 \%$ & \\
\hline Missing & 15 & $16.7 \%$ & \\
\hline \multicolumn{4}{|l|}{$\begin{array}{l}\text { Is each discipline given equal } \\
\text { time/significance in the team meeting? }\end{array}$} \\
\hline Yes & 37 & $41.1 \%$ & \\
\hline No & 38 & $42.2 \%$ & \\
\hline Missing & 15 & $16.7 \%$ & \\
\hline
\end{tabular}




\begin{tabular}{|llll|}
\hline Survey items & N & & Range \\
Yes & 46 & $51.5 \%$ & \\
No & 29 & $32.3 \%$ & \\
Missing & 15 & $16.7 \%$ & \\
\hline
\end{tabular}

